\title{
The mystery of Mystriosaurus: Redescribing the poorly known Early Jurassic teleosauroid thalattosuchians Mystriosaurus laurillardi and Steneosaurus brevior
}

Sven Sachs, Michela M. Johnson, Mark T. Young, and Pascal Abel

Acta Palaeontologica Polonica 64 (3), 2019: 565-579 doi:https://doi.org/10.4202/app.00557.2018

The genus Mystriosaurus, established by Kaup in 1834, was one of the first thalattosuchian genera to be named. The holotype, an incomplete skull from the lower Toarcian Posidonienschiefer Formation of Altdorf (Bavaria, southern Germany), is poorly known with a convoluted taxonomic history. For the past 60 years, Mystriosaurus has been considered a subjective junior synonym of Steneosaurus. However, our reassessment of the Mystriosaurus laurillardi holotype demonstrates that it is a distinct and valid taxon. Moreover, we find the holotype of "Steneosaurus" brevior, an almost complete skull from the lower Toarcian Whitby Mudstone Formation of Whitby (Yorkshire, UK), to be a subjective junior synonym of $M$. laurillardi. Mystriosaurus is diagnosed in having: a heavily and extensively ornamented skull; large and numerous neurovascular foramina on the premaxillae, maxillae and dentaries; anteriorly oriented external nares; and four teeth per premaxilla. Our phylogenetic analyses reveal $M$. laurillardi to be distantly related to Steneosaurus bollensis, supporting our contention that they are different taxa. Interestingly, our analyses hint that Mystriosaurus may be more closely related to the Chinese teleosauroid (previously known as Peipehsuchus) than any European form.

Key words: Thalattosuchia, Teleosauroidea, Mystriosaurus, Jurassic, Toarcian Posidonienschiefer Formation, Whitby Mudstone Formation, Germany, UK.

Sven Sachs [ㅈachs.Pal@gmail.com], Naturkunde-Museum Bielefeld, Abteilung Geowissenschaften, Adenauerplatz 2, 33602 Bielefeld, Germany; Im Hof 9, 51766 Engelskirchen, Germany (address for correspondence). Michela M. Johnson [Michela.Johnson@ed.ac.uk] and Mark T. Young [Mark.Young@ed.ac.uk ], School of GeoSciences, Grant Institute, University of Edinburgh, James Hutton Road, Edinburgh, EH9 3FE, UK. Pascal Abel [pascal.abel@ifg.uni-tuebingen.de], Senckenberg Centre for Human Evolution and Palaeoenvironment, Eberhard-Karls-Universität Tübingen, Sigwartstraße 10, 72076 Tübingen, Germany. 
This is an open-access article distributed under the terms of the Creative Commons Attribution License (for details please see creativecommons.org), which permits unrestricted use, distribution, and reproduction in any medium, provided the original author and source are credited.

Forif Full text $(7,310.1 \mathrm{kB})$ ।

FoFif- Supplementary file $(1,382.3 \mathrm{kB})$ 